\title{
Article \\ $\beta$-Aminobutyric Acid Induced Resistance against Alternaria Fruit Rot in Apple Fruits
}

\author{
Lior Gur ${ }^{1,2}\left(\mathbb{D}\right.$, Moshe Reuveni ${ }^{1, *}$ and Yigal Cohen ${ }^{2}(\mathbb{D}$ \\ 1 Shamir Research Institute, University of Haifa, Katzrin 1290000, Israel; liogur@gmail.com \\ 2 Faculty of Life Sciences, Bar-Ilan University, Ramat Gan 5290002, Israel; yigal.cohen1@gmail.com \\ * Correspondence: mreuveni@research.haifa.ac.il; Tel.: +972-54-777-2447
}

Citation: Gur, L.; Reuveni, M.;

Cohen, Y. $\beta$-Aminobutyric Acid

Induced Resistance against Alternaria Fruit Rot in Apple Fruits. J. Fungi 2021, 7, 564. https://doi.org/ $10.3390 /$ jof7070564

Academic Editors: Antonieta De Cal, Inmaculada Larena and Paloma Melgarejo

Received: 17 June 2021

Accepted: 12 July 2021

Published: 14 July 2021

Publisher's Note: MDPI stays neutral with regard to jurisdictional claims in published maps and institutional affiliations.

Copyright: (c) 2021 by the authors. Licensee MDPI, Basel, Switzerland. This article is an open access article distributed under the terms and conditions of the Creative Commons Attribution (CC BY) license (https:/ / creativecommons.org/licenses/by/ $4.0 /)$.

\begin{abstract}
Fruit body rot and calyx rot caused by Alternaria alternata f. sp. mali is an important disease of apple worldwide. The disease has recently become severe in cv. Pink Lady apple in Israel to an extent that has never been reported elsewhere in the world. No alternative control measures of the disease except fungicides are known. Here, we show for the first time that DL- $\beta$-aminobutyric acid (BABA) induces resistance against Alternaria fruit rot (AFR) in apple fruits in the laboratory and in the orchard. AFR was inhibited in fruits treated with BABA of $1000 \mu \mathrm{g} / \mathrm{mL}$. BABA did not inhibit spore germination or mycelial growth of the pathogen in vitro (up to $2000 \mu \mathrm{g} / \mathrm{mL}$ ). It was most inhibitory when applied 4 days prior to inoculation of detached fruits. BABA inhibited AFR also curatively when applied at $24 \mathrm{~h}$ post inoculation. Five other isomers of aminobutyric acid failed to protect the fruits from rot formation. Three field trials in commercial apple orchards proved that BABA was as protective against AFR as the commercial standard fungicidal mixture of azoxystrobin and difenoconazole. This research suggests that BABA may serve as a resistance inducer in apple against AFR. It can be used as an adequate alternative to the currently used fungicides or integrated in disease management programs to reduce fungicide load and buildup of fungicide resistance.
\end{abstract}

Keywords: Alternaria mali; Alternaria alternata apple pathotype; BABA; disease control; induced resistance; plant defense activators; priming; integrated pest-management

\section{Introduction}

Alternaria leaf blotch and fruit spot of apple (Malus domestica Borkh), caused by the fungus Alternaria alternata f. sp. mali (syn. Alternaria mali Roberts, or Alternaria alternata apple pathotype) [1-3], is an important disease of apple in many countries [4-10], including Israel [11]. The disease affects cultivars such as Golden Delicious, Starking Delicious, Gala and Pink Lady [5,8,11-13]. In most cases, fruit symptoms are usually limited to small, corky, dark lesions, often associated with the lenticels [12]. The pathogen may cause soft rot, particularly when the skin is wounded by mechanical damage or insects [14-16] or has cracks around the fruit calyx [17]. Severe outbreaks of apple fruit rot were observed in cv. Pink Lady in northern Israel [11]. Because large lesions and rots are the common symptoms in fruits in Israel, unlike the small spots seen in other countries, we named the disease 'Alternaria fruit rot' (AFR) [18]. Heavy infection with AFR is rare in other countries [16,19]. Lesions on the fruit body and adjacent to cracks around the calyx develop to form large, dark, rotted areas which can destroy $80 \%$ of the fruits in some orchards [11]. Whereas leaf infection and defoliation are the main damage caused by A. alternata $\mathrm{f}$. sp. mali in most growing areas in the world [16,19], fruit rot is the major problem in Israel [11]. Pink Lady is the most valuable cultivar among apple cultivars grown in Israel due to its taste and flavor. Therefore, AFR is a major factor reducing apple fruit quality with a severe economic impact.

In previous studies, we showed that AFR may be controlled by foliar fungicidal sprays [20]. Integrated Pest Management (IPM) in the orchards encourages the use of 
alternative methods. The introduction of the plant defense activator DL- $\beta$-aminobutyric acid (BABA) by Cohen [21-23] provided a new option for chemical management of plant diseases based on the induction of host resistance.

BABA was shown to protect about 40 plant species against about 80 pests, including protista, bacteria, oomycetes, fungi, nematodes, arthropods and viruses. However, only a few studies showed efficacy of BABA against tree diseases [24-28].

The objective of the present study was to evaluate the inhibitory effect of BABA on A. alternata f. sp. mali in vitro, and on rot formation in apple fruit in the laboratory and the field. The data suggest that BABA induces protection against AFR in the laboratory and provides good control of apple rot in cv. Pink Lady in the orchard.

\section{Materials and Methods}

\subsection{Chemicals}

BABA (DL-3-amino-n-butanoic acid, DL- $\beta$-aminobutyric acid) was purchased from Sigma, Israel. AABA ( $\alpha$-aminobutyric acid), GABA ( $\gamma$-aminobutyric acid), $\alpha$-amino-isobutyric acid, DL- $\beta$-iso BABA and 3 -aminopropionic acid ( $\beta$-alanine) were all purchased from Sigma-Aldrich (Rehovot, IL, Israel). These compounds were used for in vitro studies in the laboratory or with detached fruits. The efficacy of BABA was compared with that of the fungicide Score 250 SC (Syngenta, Basel, Switzerland), containing difenoconazole, a sterol demethylation inhibitor (DMI, FRAC Code 3) [29] and the commercial pre-mixed fungicide Ortiva-Top 325 SC (Syngenta, Basel, Switzerland) comprising azoxystrobin (FRAC Code 11) at $200 \mathrm{~g} / \mathrm{L}$ and difenoconazole at $125 \mathrm{~g} / \mathrm{L}$. A wettable powder (25 WP) formulation of BABA (gratefully provided by Syngenta) was also used in field experiments. All concentrations in laboratory experiments are presented as $\mu \mathrm{g} / \mathrm{mL}$ of active ingredient (a.i.), unless stated otherwise. The efficacy of BABA in controlling Alternaria fruit rot in apple fruits in the field was compared to that of the commercial pre-mixed fungicide Ortiva-Top 325 SC.

\subsection{Pathogen}

A single-spore culture of $A$. alternata $\mathrm{f}$. sp. mali grown on potato dextrose agar (PDA $39 \mathrm{~g} / \mathrm{L}$, Difco (Detroit, MI, USA)) was maintained at $25^{\circ} \mathrm{C}$ in $9 \mathrm{~cm}$ Petri dishes in the dark for 10-12 days until conidia were produced on developed colonies. Conidia were harvested from PDA plates by adding $3 \mathrm{~mL}$ of sterile distilled water to each plate and gently rubbing the sporulating mycelial mass with a bent glass rod. Spore concentration was adjusted with the aid of a hemocytometer to $5 \times 10^{5}$ spores $\mathrm{mL}^{-1}$ [18]. A highly virulent isolate, PL-SH-B-3011, isolated from body rot of a Pink Lady fruit grown in Sha'al orchard $\left(33^{\circ} 07^{\prime} 43^{\prime \prime} \mathrm{N}, 35^{\circ} 43^{\prime} 34^{\prime \prime} \mathrm{E}\right)$ in 2011 , was used in all experiments [11].

\subsection{In Vitro Assays}

\subsubsection{Germination}

Fresh conidial suspensions were kept in $2 \mathrm{~mL}$ tubes and mixed with an aqueous suspension of BABA to achieve a final concentration of $0,10,100,1000$ and $2000 \mu \mathrm{g} / \mathrm{mL}$, or the pre-mixture azoxystrobin plus difenoconazole of $162.5 \mu \mathrm{g} / \mathrm{mL}$ (a.i) at a uniform conidial concentration of $2 \times 10^{4} \mathrm{~mL}^{-1}$. A $70 \mu \mathrm{L}$ aliquot of each mixture was pipetted into depressions of microscope slides (three per treatment) and incubated on a wet filter paper in $9 \mathrm{~cm}$ Petri dishes at $25^{\circ} \mathrm{C}$ for $20 \mathrm{~h}$ in the dark. The number of germinating conidia was counted in each depression at $\times 100$ magnification and percent germination determined. Each experiment was conducted twice.

\subsubsection{Mycelial Growth}

Two $5 \mathrm{~mm}$ agar disks bearing A. alternata f. sp. mali were taken from the edge of a freshly growing colony and placed in a $9 \mathrm{~cm}$ petri dish containing PDA amended with 0,10,100, 1000 or $2000 \mu \mathrm{g} / \mathrm{mL}$ BABA, or 50 or $162.5 \mu \mathrm{g} / \mathrm{mL}$ (a.i) difenoconazole and the pre-mixture azoxystrobin plus difenoconazole, respectively. Cultures were incubated at 
$25{ }^{\circ} \mathrm{C}$ in the dark and colony diameter was recorded after 3,4 and 5 days. Three petri dishes were used for each treatment concentration, and experiments were conducted twice.

\subsubsection{Growth in Liquid Medium}

The activity of BABA, difenoconazole and the pre-mixture azoxystrobin plus difenoconazole on fungal growth was also examined in liquid medium. One milliliter of potato dextrose broth (PDB $24 \mathrm{~g} / \mathrm{L}$, Difco) containing the following compounds was added to sterile 48-well plates: BABA of 0, 10, 100, 1000 or $2000 \mu \mathrm{g} / \mathrm{mL}$; difenoconazole of $25 \mu \mathrm{g} / \mathrm{mL}$ (a.i); and the pre-mixture azoxystrobin plus difenoconazole of $32.5 \mu \mathrm{g} / \mathrm{mL}(\mathrm{a} / \mathrm{i})$. To each well, $4 \mu \mathrm{L}$ of conidial suspension $\left(2.5 \times 10^{4}\right.$ conidia $\mathrm{mL}^{-1}, 100$ conidia per well $)$ was added. Five wells were used for each dose treatment. The plates were stirred $(30 \mathrm{rpm})$ at $25^{\circ} \mathrm{C}$ in the dark. Seven days after inoculation, the growing mycelial was taken out with the aid of tweezers, blotted dry on filter paper for $1 \mathrm{~h}$ in a chemical fume hood and weighed.

\subsection{Efficacy in Detached Fruits}

\subsubsection{Inoculation Procedure}

Detached fruits were inoculated as described by Gur et al. [11]. Briefly, mature fruits, cv. Pink Lady from untreated trees, were brought from the orchard, washed with water, blotted dry with a paper towel, sprayed with $90 \%$ ethanol and allowed to dry at room temperature. Conidia were harvested from PDA cultures by adding $3 \mathrm{~mL}$ of sterile distilled water to each dish and gently rubbing the sporulating mycelial mats with a bent glass rod. The spore concentration was adjusted with the aid of a hemocytometer to $5 \times 10^{5}$ spores $/ \mathrm{mL}$. Each fruit was wounded at six points on its surface with a $2 \mathrm{~mm}$-diameter sterile plastic tip to a depth of $\sim 3 \mathrm{~mm}$ and then inoculated by pipetting $10 \mu \mathrm{L}$ conidial suspension to each wound. Following inoculation, fruits were placed on trays containing wet filter paper, covered with plastic bags to maintain high humidity and held covered in a growth chamber $\left(25^{\circ} \mathrm{C}\right)$ in the dark for 13 days.

\subsubsection{Experiment 1. Effect of Application Date on Rot Development}

Aliquots of $300 \mu \mathrm{L}$ of BABA $(1000 \mu \mathrm{g} / \mathrm{mL})$ were injected to each of six sites on each of three fruits per treatment, with the aid of an insulin injector, through the fruit skin into the mesoderm to a depth of $\sim 12 \mathrm{~mm}$. Injection was carried out at 0, 1, 2, 3 and 4 days before inoculation, or one day after inoculation. Injected sites were marked, and fruits were kept in the growth chamber at $25{ }^{\circ} \mathrm{C}$ until inoculated. Fruits injected with sterile water and fruits inoculated with conidial suspension in water served as controls.

\subsubsection{Experiment 2. Effect of BABA Concentration on Rot Development}

BABA of $0,10,100,500,1000$ and $2000 \mu \mathrm{g} / \mathrm{mL}$ were injected into fruits four days before inoculation as described above ( $300 \mu \mathrm{L}$ per concentration; six sites on three fruits/treatment) Each injected site was marked, and fruits were kept in the growth chamber at $25^{\circ} \mathrm{C}$ until inoculation was performed in each injected site as described above. Fruits injected with a mixture of BABA with conidial suspension, sterile water only or with conidial suspension in water served as controls.

\subsubsection{Experiment 3. Efficacy of Isomers of BABA}

Aqueous solutions of BABA, AABA ( $\alpha$-aminobutyric acid), GABA ( $\gamma$-aminobutyric acid), $\alpha$-amino-iso-butyric acid, DL- $\beta$-iso-BABA or $\beta$-alanine, all at $1000 \mu \mathrm{g} / \mathrm{mL}$, were each injected into fruits as described above, four days before inoculation, to each of six sites on each of three fruits per treatment. Fruits were inoculated and incubated as described above and 14 days after inoculation the rot diameter was recorded.

\subsection{Efficacy in the Orchard}

Three field experiments were conducted during August to October in commercial orchards of apple cv. Pink Lady in the Golan region in Israel. Fertilization, irrigation 
and other cultural practices in the orchards were as recommended by the Extension Service of the Ministry of Agriculture, Israel. The annual rainfall was 750-850 mm (Israel Meteorological Service, www.ims.gov.il, accessed on 2 March 2020), all of which occurs during the winter (October-April). During the spring (April-May), temperatures were moderate $\left(10-25^{\circ} \mathrm{C}\right)$, accompanied by leaf wetness due to rain events. In the summer (JuneSeptember) the average midday relative humidity $(\mathrm{RH})$ and temperature were $35-40 \%$ and $30{ }^{\circ} \mathrm{C}$, respectively. Skies were cloudless during most of the summer. Night temperature occasionally fell to $14-20^{\circ} \mathrm{C}$ between May to August, and dew accumulated on leaf surfaces during some nights.

\subsubsection{Field Experiment 1 and 2}

Two field experiments were conducted, in 2012 and 2020. BABA (DL- $\beta$-aminobutyric acid, $0.1 \% w / v)$ and the pre-mixture azoxystrobin plus difenoconazole $(0.05 \% w / v)$ were tested in Ein Zivan orchard on cv. Pink Lady trees. In experiment 1, five shoots bearing 2 fruits each were selected and labeled on each of five different trees per treatment (10 fruits per treatment). In experiment 2 , six shoots bearing 3 fruits each were selected and labeled on each of six different trees per treatment (18 fruit per treatment). Each fruit (mean diameter $=68 \mathrm{~mm}$ ) was wounded with a $1.3 \mathrm{~mm}$-diameter needle at four different sites. Branches including fruits were then sprayed using a handy sprayer with about $10 \mathrm{~mL}$ solution of each compound per branch. Shoots with non-treated fruits on untreated trees served as controls. Four days later, fruits were inoculated as described in Gur et al. [18]. Briefly, a conidial suspension of A. alternata f. sp. mali $\left(5 \times 10^{5}\right.$ spores $\left.\mathrm{mL}^{-1}\right)$ was prepared and held on ice until fruits were spray-inoculated in the orchard. Following spray inoculation, each fruit was covered with a wet plastic bag to maintain high humidity. Bags were removed on the following morning. Thirteen days after inoculation, the diameter of fruit rot developed on the skin and mesocarp of each sprayed and inoculated fruit was measured.

\subsubsection{Field Experiment 3}

BABA (formulated as $25 \mathrm{WP})(0.1 \% w / v$ a.i) and the pre-mixture azoxystrobin plus difenoconazole $(0.05 \% w / v)$ were tested at Ein Zivan orchard on cv. Pink Lady trees in 2012. Five shoots containing 1-2 fruits each were selected and labeled on five different trees per treatment (a total of 25 branches per treatment). Each compound was sprayed six times at 10 day intervals starting at August 26 (average fruit size of $55 \mathrm{~mm}$ diameter). Untreated fruits on untreated trees served as controls. As disease did not appear naturally in this orchard, an artificial inoculation was performed four days following the last application in the same manner as described above. The diameter of fruit rot that developed on the skin and mesocarp of each sprayed and inoculated fruit was measured.

\subsection{Data Analysis}

Each laboratory experiment was conducted at least twice. All data were analyzed with the GLM statistical software JMP statistics package version 14.1.0 (SAS, Cary, NC, USA). For the mycelial growth on PDA or PDB, detached fruits experiments and field experiment, analysis of variance (ANOVA) was applied to colony weight, and colony or fruit rot diameters measurements. Fisher's LSD K-ratio $t$-test was applied, to determine whether differences between treatments were significant at $\alpha=0.05$. In field experiments, treatments were arranged in a randomized complete block design.

\section{Results}

\subsection{In Vitro Assays}

\subsubsection{Germination}

Mean conidial germination of A. alternata f. sp. mali in water was $94.7 \%$ (Table 1 ). Conidial germination was insensitive to BABA: percent germination in BABA of 10, 100, 1000 and $2000 \mu \mathrm{g} / \mathrm{mL}$ at $20 \mathrm{~h}$ ranged between 88.6-96.2\% (Table 1). In contrast, germination 
in the pre-mixture azoxystrobin plus difenoconazole of $162.5 \mu \mathrm{g} / \mathrm{mL}$ a.i was completely inhibited.

Table 1. Activity of BABA and the pre-mixture azoxystrobin plus difenoconazole on A. alternata f. sp. mali conidia germination.

\begin{tabular}{ccc}
\hline Treatment (Conc. $\mu \mathrm{g} / \mathrm{mL})$ & \% Germinated Conidia & SE $^{2}$ \\
\hline Control & 94.7 & 2.80 \\
\hline BABA 10 & 93.7 & 3.33 \\
\hline BABA 100 & 92.5 & 2.75 \\
\hline BABA 1000 & 95.4 & 2.46 \\
\hline BABA 2000 & 88.6 & 3.16 \\
\hline Azoxy + Difeno $162.5^{1}$ & $0 *$ & 0
\end{tabular}

${ }_{1}^{1}$ Concentration given in $\mu \mathrm{g} / \mathrm{mL}$ a.i of the prepacked mixture of azoxystrobin $(200 \mathrm{~g} / \mathrm{L})+$ difenoconazole $(125 \mathrm{~g} / \mathrm{L})$.

${ }^{2} \mathrm{SE}=$ standard error. * Significantly different $(p<0.05$, Fisher's LSD K-ratio $t$-test).

\subsubsection{Mycelial Growth}

Mycelial growth of A. alternata f. sp. mali in vitro was similarly insensitive to BABA even at $2000 \mu \mathrm{g} / \mathrm{mL}$ (Figure 1A,B). In contrast, difenoconazole and the pre-mixture azoxystrobin plus difenoconazole provided $93 \%$ and $83 \%$ inhibition of mycelial growth, respectively, compared to water control (Figure 1A,B).

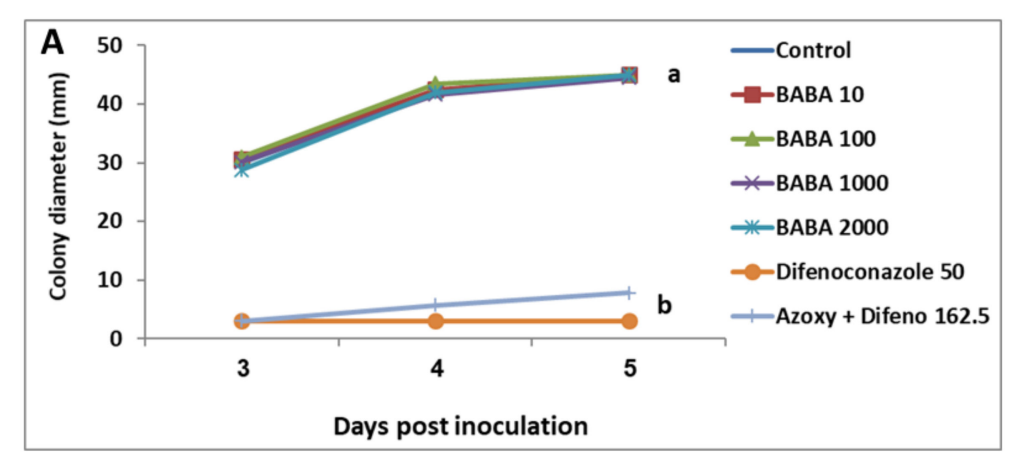

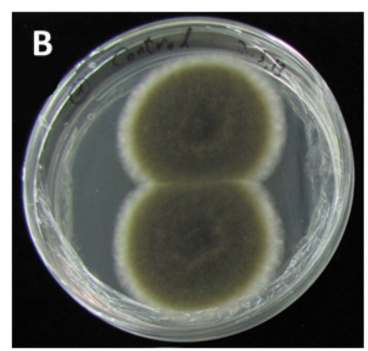

Control

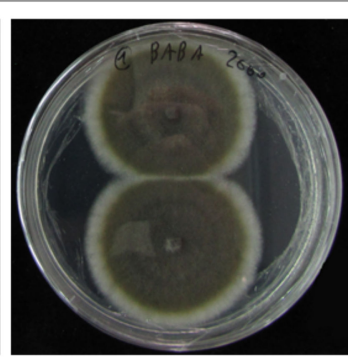

BABA 2000

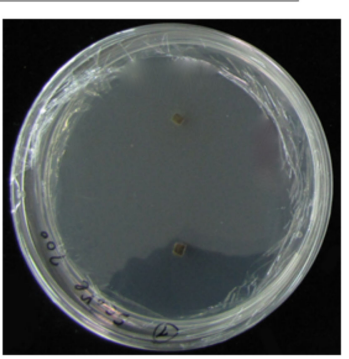

Difenoconazole 50

Figure 1. (A) Activity of BABA on mycelial growth of A. alternata f. sp. mali in comparison to difenoconazole (Difeno) and pre-mixture azoxystrobin plus difenoconazole (Azoxy + Difeno). Concentrations are given in $\mu \mathrm{g}$ per $\mathrm{ml}$ active ingredient. Different letters on curves indicate a significant $(p<0.05)$ difference between treatment (LSD test). (B) Activity of BABA and Score on mycelial growth of A. alternata f. sp. mali in PDA cultures. Concentrations are given in $\mu \mathrm{g}$ per $\mathrm{mL}$ active ingredient.

\subsubsection{Growth in Liquid Medium}

BABA of up to $2000 \mu \mathrm{g} / \mathrm{mL}$ had a small, though significant, inhibitory effect on fungal growth in liquid medium. The average mycelial weight of control cultures was $46 \pm 5 \mathrm{mg}$, compared to $33 \pm 3.5 \mathrm{mg}$ in all BABA treatments (Figure 2). The pre-mixture 
azoxystrobin plus difenoconazole inhibited fungal growth by $72 \%$, relative to control, while difenoconazole alone inhibited fungal growth completely (Figure 2).
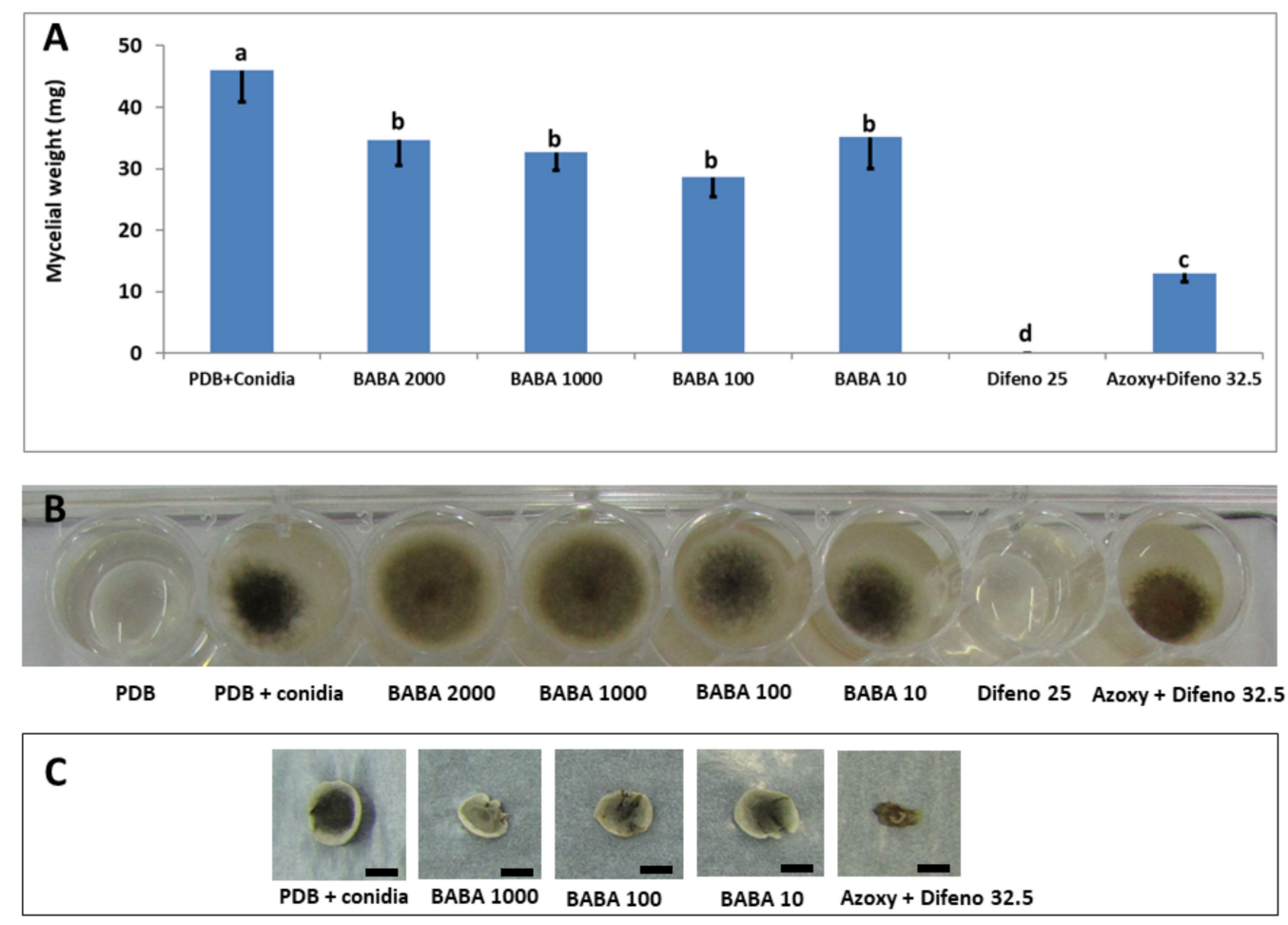

Figure 2. (A) Activity of BABA, difenoconazole (Difeno) and pre-mixture azoxystrobin plus difenoconazole (Azoxy + Difeno) on growth of A. alternata f. sp. mali in liquid medium. Concentrations are given in $\mu \mathrm{g} / \mathrm{mL}$ of active ingredient. Bars represent the standard error of the mean. Different letters on columns indicate significant differences $(p<0.05)$ between treatments (Fisher's LSD K-ratio $t$-test). (B) Representative wells of various treatments at seven days post inoculation. (C) Representative mycelial mats from each treatment on a blotting paper. Bar $=10 \mathrm{~mm}$.

\subsection{Experiments on Detached Fruits}

\subsubsection{Effect of Application Date on Rot Development}

Induced resistance by BABA was dependent on whether it was applied before or after inoculation. BABA was most effective in inducing resistance against Alternaria fruit rot when injected to the fruits at four days before inoculation (Figure 3). BABA was slightly effective even when applied $24 \mathrm{~h}$ post inoculation (Figure 3).

\subsubsection{Effect of BABA Concentration on Rot Development}

Fruit rot formation by A. alternata f. sp. mali was inhibited by BABA when injected into fruit four days before inoculation in a dose-dependent manner. BABA of $1000 \mu \mathrm{g} / \mathrm{mL}$ was the most inhibitory, providing an $82 \%$ decrease in apple blotch on fruits compared to untreated inoculated control fruits (Figure 4). A higher concentration did not improve control of rot formation.

\subsubsection{Efficacy of Various Isomers of BABA}

AABA ( $\alpha$-aminobutyric acid), GABA ( $\gamma$-aminobutyric acid), $\alpha$-amino-iso-butyric acid, DL- $\beta$-iso-BABA and 3-aminopropionic acid ( $\beta$-alanine), each applied at $1000 \mu \mathrm{g} / \mathrm{mL}$, were all ineffective in controlling AFR. BABA at this dose provided $63 \%$ inhibition of the symptoms relative to non-treated inoculated controls (Figure 5). Fruit rot diameter in non-treated inoculated control fruits ranged between 23 and $25 \mathrm{~mm}$. 


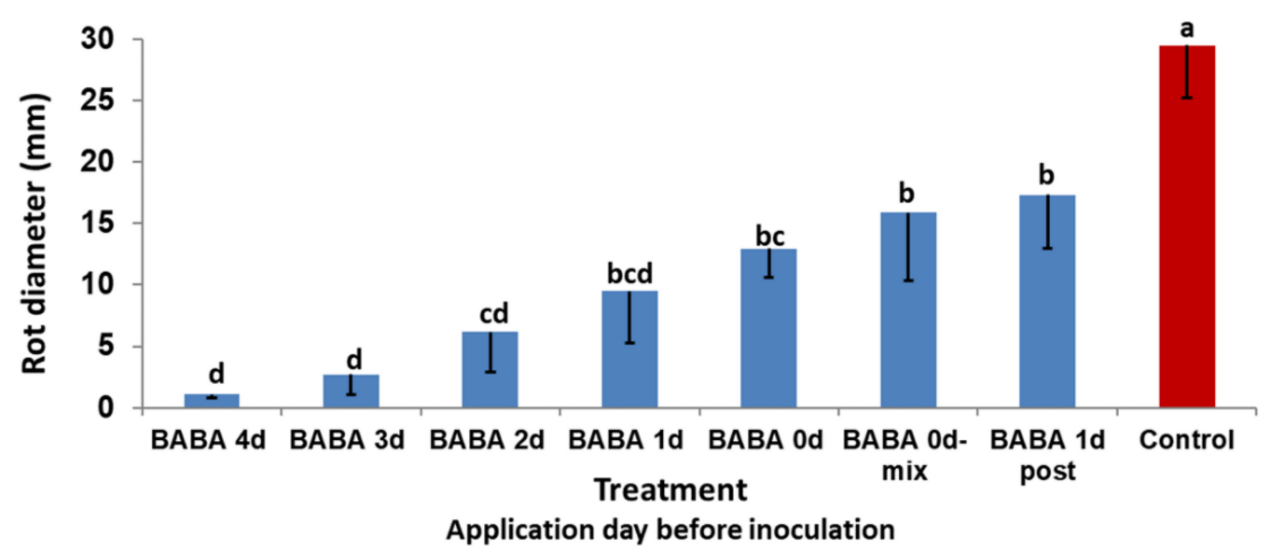

Figure 3. Inhibition of AFR development caused by A. alternata f. sp. mali in detached apple fruits treated with BABA at various days before or after inoculation. In treatment 'BABA 0 d-mix', a mixture of BABA with conidial suspension was used for inoculation. The fruit rot diameter produced at 13 days post inoculation in each inoculation site is shown. Bars represent the standard error of the mean. Different letters on columns indicate significant differences between treatments $(p<0.05$, Fisher's LSD K-ratio $t$-test).

A

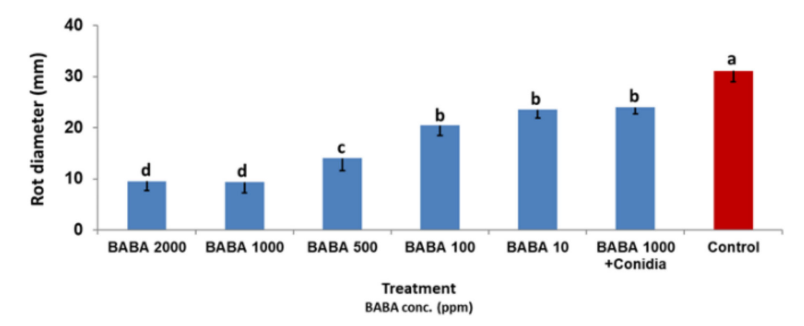

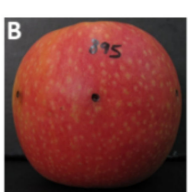

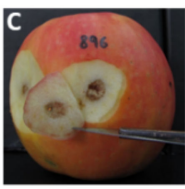

BABA 2000
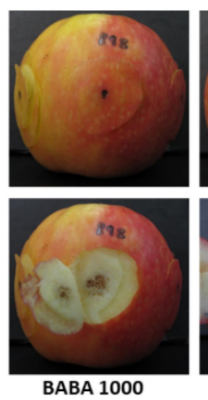
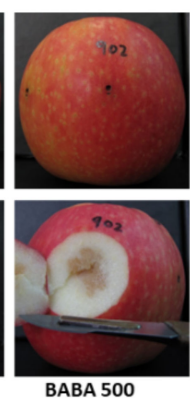
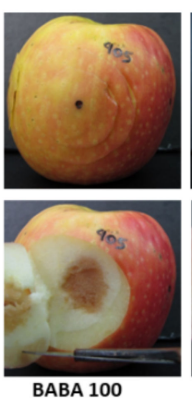
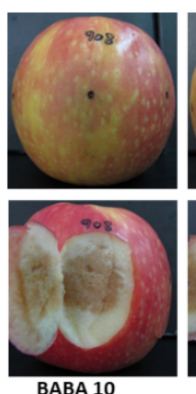

BABA 10
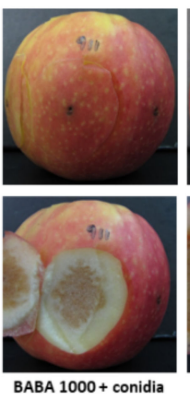
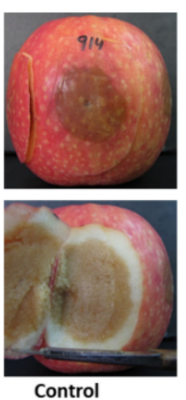

Figure 4. (A) Resistance against AFR caused by A. alternata f. sp. mali induced in detached apple fruits by BABA of various concentrations. In treatment 'BABA $1000+$ conidia', a mixture of BABA with conidial suspension was used for inoculation. Inoculated fruits were incubated in a moist chamber at $25{ }^{\circ} \mathrm{C}$ for 13 days. The mean values represent fruit rot diameter produced in each inoculation site of each of three fruits per concentration. Bars represent the standard error of the mean. Different letters on columns indicate significant differences between treatments $(p<0.05$, Fisher's LSD K-ratio $t$-test). (B) Photos of rot developed on skin of fruits treated with BABA at various concentrations, and untreated control fruit. (C) Photos of rot developed in the mesoderm of fruits treated with BABA of various concentrations. Control $=$ untreated inoculated fruit. 
A

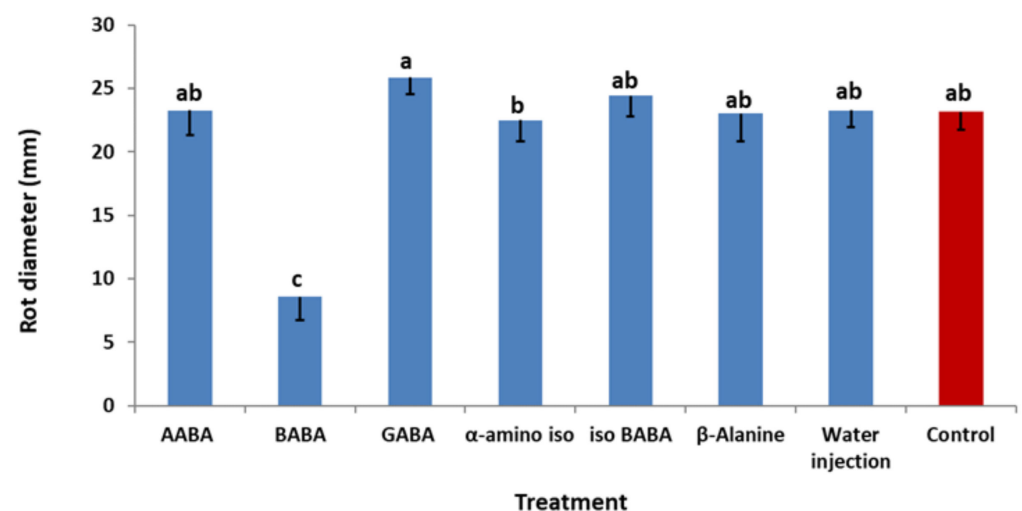

B

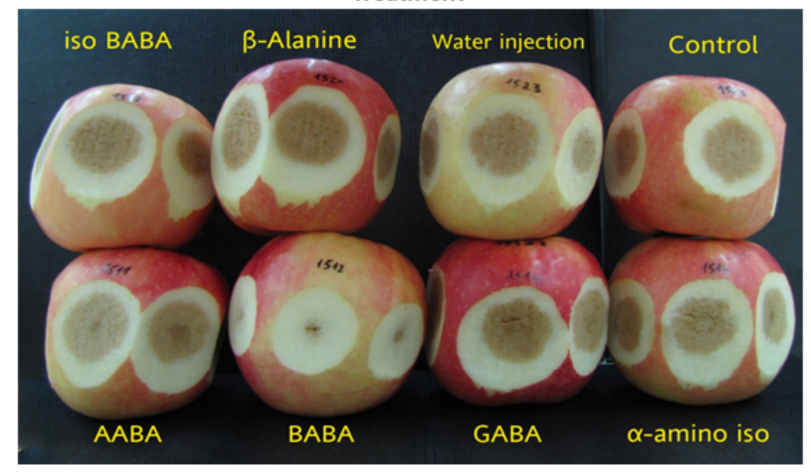

Figure 5. (A) Activity of various isomers of BABA on rot development in detached fruits. Bars represent the standard error of the mean. Different letters on columns indicate significant differences between treatments ( $p<0.05$, Fisher's LSD K-ratio $t$-test). (B) Photos of rot developed in mesoderm of fruits treated with various isomers of BABA (all at $1000 \mathrm{ppm}$ ). Control = untreated inoculated fruit.

\subsection{Field Experiments}

In both experiment 1 and 2, a single foliar application of BABA or of azoxystrobin plus difenoconazole applied to fruits 4 days before inoculation with $A$. alternata $\mathrm{f}$. sp. mali, provided similar protection of the fruits, reducing fruit rot formation by $45-67 \%$ and $44-74 \%$, respectively, compare to non-treated fruits (Figure 6A,B and Figure 7).

In experiment 3 , formulated BABA or azoxystrobin plus difenoconazole similarly reduced fruit rot formation by $55 \%$ and $70 \%$, respectively, compare to fruits on non-treated trees (Figure 8). 

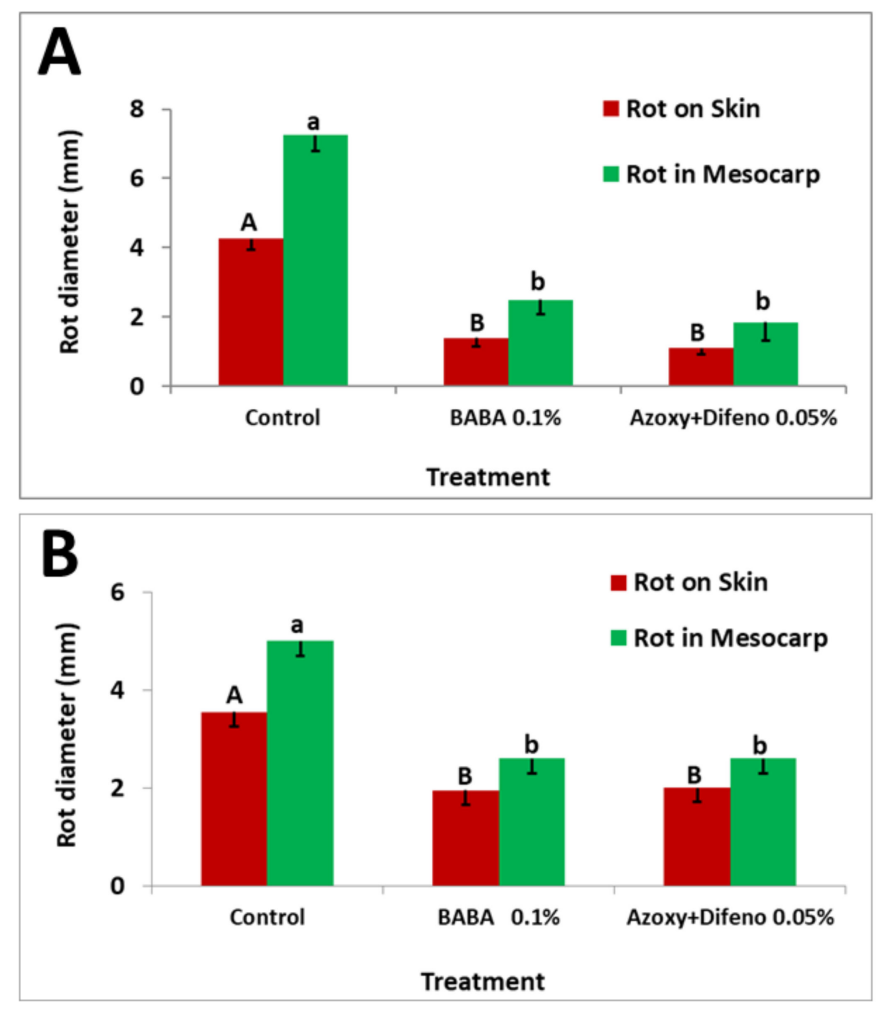

Figure 6. Efficacy of BABA and the pre-mixture azoxystrobin plus difenoconazole (Azoxy + Difeno) sprayed four days before inoculation on rot development in Pink Lady apple fruits in the orchard (A) Experiment 1. (B) Experiment 2. Mean values of lesion diameter on skin (uppercase letters) or in mesocarp (lowercase letters) above columns followed by different letters indicate significant $(p<0.05)$ differences between treatments (Fisher's LSD $t$-test). Bars represent the standard error of the mean.
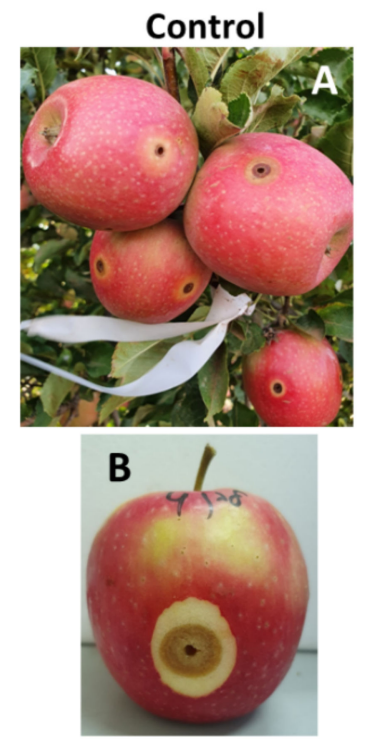

DL-BABA
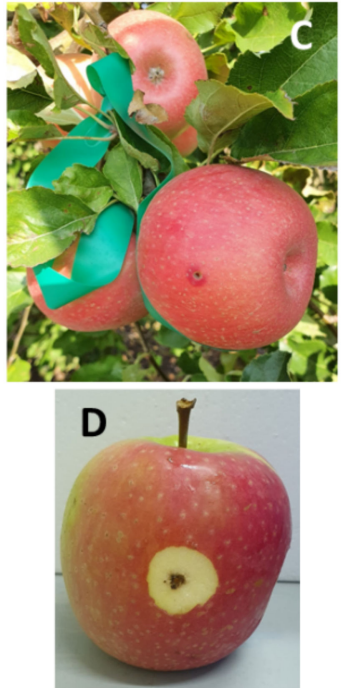

Azoxy + Difeno
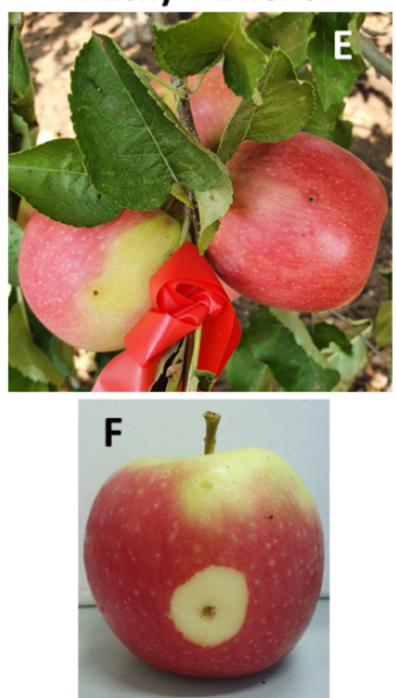

Figure 7. Fruit rot development following artificial inoculation in the orchard: $(\mathbf{A}, \mathbf{B})$. Rot developed on untreated fruits; (C,D) Rot developed on fruits treated with BABA; $(\mathbf{E}, \mathbf{F})$ Rot developed on fruit treated with the pre-mixture azoxystrobin plus difenoconazole (Azoxy + Difeno). 


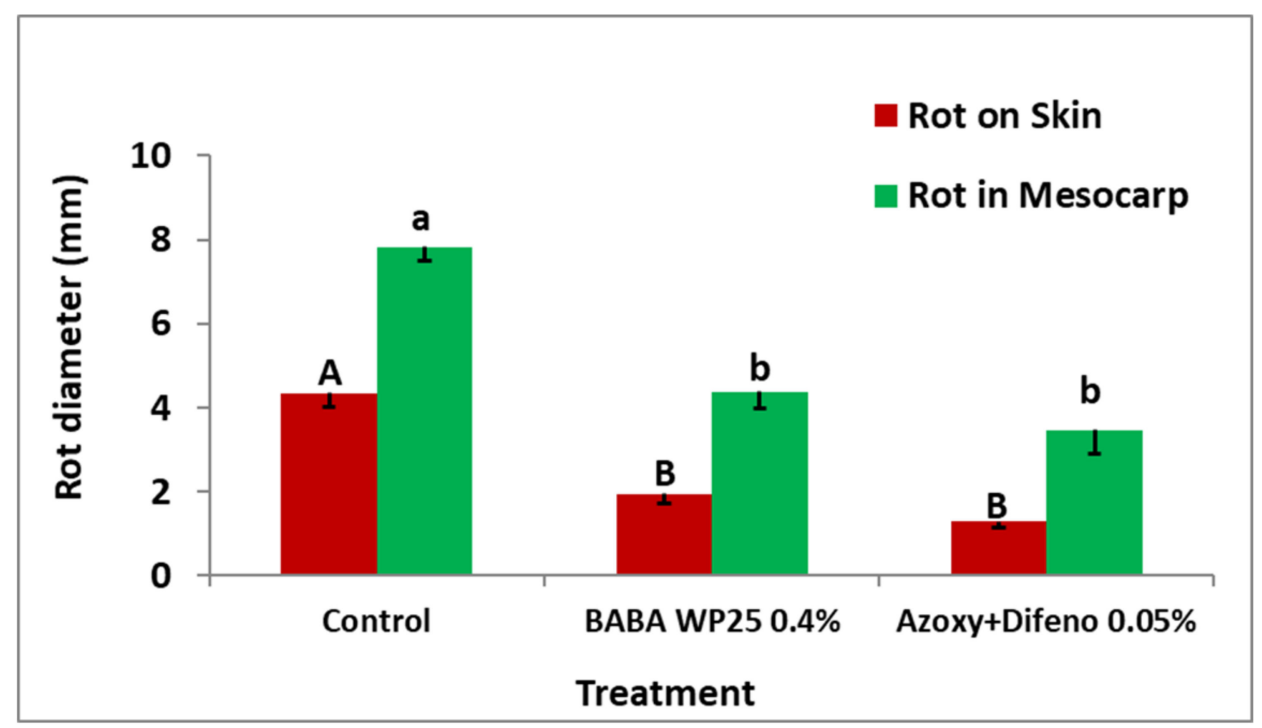

Figure 8. Efficacy of six foliar applications of BABA WP25 and the pre-mixture azoxystrobin plus difenoconazole (Azoxy + Difeno) on rot development in Pink Lady apple fruits in the orchard (Experiment 3). Mean values of lesion diameter on skin (uppercase letters) or in mesocarp (lowercase letters) above columns followed by different letters indicate on significant $(p<0.05)$ differences between treatments (Fisher's LSD $t$-test). Bars represent the standard error of the mean.

\section{Discussion}

Severe outbreaks of apple fruit rot occurred in recent years in orchards of cv. Pink Lady in Israel $[11,20]$. Such severe fruit rot in cv. Pink Lady is not known elsewhere in the world. The causal pathogen was identified as Alternaria alternata f. sp. mali and we named the disease Alternaria Fruit Rot (AFR) [11]. Previous studies showed that fungicidal mixtures, such as the pre-mixture azoxystrobin plus difenoconazole, the pre-mixture captan plus tebuconazole and others, effectively controlled Alternaria fruit rot in apple orchards [18,20].

Plant defense activators can provide a new option for chemical management of plant diseases based on priming of host resistance [30]. There are a few reports showing resistance of fruits against fungal infection induced by plant activators [25], but no study compared their efficacy with commercial fungicides. This lack of information encouraged us to examine the activity of BABA in inducing resistance against $A$. alternata f. sp. mali in apple fruits. This compound was reported to induce resistance against a wide range of plant diseases [25].

We show here that BABA had no direct effect on the growth of A. alternata f. sp. mali in vitro. Spore germination and mycelial growth were insensitive to BABA (Table 1 and Figure 1). This confirms previous findings, showing that BABA had no antifungal activity in vitro [25]. In contrast, Elsherbiny et al. [31] reported that BABA of $125 \mathrm{mM}$ significantly inhibited mycelial growth, spore germination and germ tube elongation of Penicillium digitatum. They also showed that application of BABA of $125 \mathrm{mM}$ to orange fruits inoculated with $P$. digitatum suppressed disease incidence and disease severity and enhanced defenserelated enzymes. Ozgonen and Karatas [32], working with Alternaria mali, showed that "BABA had no significant effect on mycelial growth with increasing concentration. However, the hyphal development was decreased with increasing concentration and hyphal lysis occurred just after spore germination at 800 ppm concentration". They also showed activity of BABA against $A$. mali in leaves of young apple seedlings, but did not use apple fruits and did not show the efficacy of BABA in the field. Unlike BABA, a concentration of $162.5,16.2$ and $8 \mu \mathrm{g} / \mathrm{mL}$ of the pre-mixture azoxystrobin plus difenoconazole, captan and the pre-mixture captan plus tebuconazole, respectively, effectively inhibited conidial germination of A. alternata f. sp. mali (Table 1) [20]. 
Injection of BABA to fruits induced protection against fruit rot in a time-dependent and dose-dependent manner. The best protection was induced when BABA was applied at $1000 \mu \mathrm{g} / \mathrm{mL}$ (Figure 4). Injection at four days before inoculation induced the strongest protection against AFR (Figure 3). Injection of another inducer (benzothiadiazole-7-carbothioic acid S-methyl ester, BTH) provided less effective protection compared to BABA (L. Gur, unpublished data). BABA was also effective when applied the same day of inoculation and even $24 \mathrm{~h}$ post inoculation (Figure 3). The fact that BABA was effective post inoculation indicates a rapid activation of fruit defense. Post-infection activity of BABA was reported in grape against Plasmopara viticola [33], tobacco against Peronospora tabacina [21], tomato against Phytophthora infestans [22] and Bremia lactucae in lettuce [34].

Our data corroborate with previous reports [24,25], showing that isomers of BABA (AABA, GABA, a-amino, iso BABA and $\beta$-alanine) are ineffective in inducing resistance (Figure 5). The R-enantiomer, but not the S-enantiomer, in the racemic mixture in DL-BABA, was reported to be responsible for the induced resistance against disease [24,25].

The mode of action of BABA in apple fruits against $A$. alternata f. sp. mali is not known. Previous studies showed that BABA induces a variety of defense mechanisms, including production of phenolics, ROS, PR proteins, callose, lignin and more, depending on the host-pathogen system [21,25,34-37]. In a recent study, Schwarzenbacher et al. [38] showed that BABA interacts with $\mathrm{VOZ}$ transcription factors to regulate abscisic acid signaling and callose-associated defense against downy mildew in Arabidopsis. The reactions of apple tissue to BABA warrants a special study.

Li et al. [39] demonstrated that BABA, BTH and 2,6-dichloroisonicotinic acid (INA), individually or in combination, were effective in suppressing progress of huanglongbing (HLB) disease caused by Candidatus Liberibacter asiaticus in citrus trees in the field. These treatments also conferred a positive effect on fruit yield and quality. They concluded that plant defense inducers may be a useful strategy for management of citrus HLB disease.

The present research shows that BABA induced an effective protection of apple fruits against $A$. alternata f. sp. mali in either artificially inoculated detached apples in the laboratory or following artificial fruit inoculations in the orchard. A single foliar application of either BABA or azoxystrobin plus difenoconazole to field-grown fruits reduced fruit rot by $45-67 \%$ and $44-74 \%$, respectively, compared with non-treated control shoots (Figure 6A,B and Figure 7). A previous study showed that fruits of cv. Pink Lady acquired susceptibility to the disease at about 115 days after petal fall (DAPF) when reaching a diameter of $\geq 55 \mathrm{~mm}$ about 15 days before the appearance of fruit cracking [18]. On this basis, another experiment involving six foliar sprays of either BABA or azoxystrobin plus difenoconazole were applied to field-grown fruits. As disease did not show up, an artificial inoculation was carried out four days after the last foliar spray. Again, early applications of BABA induced protection against $A$. alternata $\mathrm{f}$. sp. mali and were as effective as the commercial fungicidal mixture azoxystrobin plus difenoconazole in reducing the formation of fruit rot (Figure 8). A similar controlling effect of BABA was observed against moldy core disease (Alternaria alternata) in apple orchards [28].

These findings may encourage the use of BABA as an alternative to the fungicidal mixture azoxystrobin plus difenoconazole for the control of Alternaria fruit rot. BABA has no direct antifungal activity and therefore poses no risk for developing fungal resistance. If incorporated in IPM programs, BABA can prevent the build-up of resistance against commercial fungicides. Reduced sensitivity of $A$. alternata f. sp. mali to polyoxin and pyraclostrobin was already reported in apple [40-42]. BABA may be alternated or combined with products such as triazoles or strobilurins, towards which the pathogen has shown reduced sensitivity, and thus extend their useful life [43].

This is the first report on the capacity of BABA to induce resistance against A. alternata f. sp. mali in detached apple fruits and Alternaria fruit rot in the field. The control of Alternaria fruit rot with a plant activator such as BABA may become a component of integrated disease management, enabling control of the disease with reduced application of fungicides. 
Author Contributions: M.R. and Y.C.-supervision; M.R., L.G. and Y.C. conceived and designed the experiments; L.G. performed the experiments and analyzed the data; M.R., L.G. and Y.C. wrote and revised the manuscript. All authors have read and agreed to the published version of the manuscript.

Funding: This study was supported by research grant No. 38427 from the Ministry of Science and Technology, State of Israel.

Institutional Review Board Statement: Not applicable.

Informed Consent Statement: Not applicable.

Data Availability Statement: This study did not report any data.

Acknowledgments: The authors thank the team of Ein-Zivan orchard and Alon Meshoolam for their valuable assistance.

Conflicts of Interest: The authors declare no conflict of interest.

\section{References}

1. Grove, G.G.; Eastwell, K.C.; Jones, A.L.; Sutton, T.B. Diseases of apple. In Apples: Botany, Production and Uses; Ferree, D.C., Warrington, I.J., Eds.; CABI Publishing: Wallingford, UK, 2003; pp. 459-488.

2. Harteveld, D.O.C.; Akinsanmi, O.A.; Drenth, A. Multiple Alternaria species groups are associated with leaf blotch and fruit spot diseases of apple in Australia. Plant Pathol. 2013, 62, 289-297. [CrossRef]

3. Woudenberg, J.H.C.; Seidl, M.F.; Groenewald, J.Z.; De Vries, M.; Stielow, J.B.; Thomma, B.P.H.J.; Crous, P.W. Alternaria section Alternaria: Species, formae speciales or pathotypes? Stud. Mycol. 2015, 82, 1-21. [CrossRef]

4. Bulajic, A.; Filajdic, N.; Babovic, M.; Sutton, T.B. First report of Alternaria mali on apples in Yugoslavia. Plant Dis. 1996, 80, 709. [CrossRef]

5. Filajdic, N.; Sutton, T.B. Identification and distribution of Alternaria mali on apples in North Carolina and susceptibility of different varieties of apples to Alternaria blotch. Plant Dis. 1991, 75, 1045-1048. [CrossRef]

6. Hanif, S.; Anjum, T.; Hafeez, R.; Akram, W.; Ali, A.; Hassan, F. First report of Alternaria mali causing core rot of apple in Pakistan. Plant Dis. 2016, 100, 1784. [CrossRef]

7. Ozgonen, H.; Karaca, G. First report of Alternaria mali causing necrotic leaf spot of apples in Turkey. Plant Pathol. 2006, 55, 578. [CrossRef]

8. Rotondo, F.; Collina, M.; Brunelli, A.; Pryor, B.M. Comparison of Alternaria spp. collected in Italy from apple with A. mali and other AM-toxin producing strains. Phytopathology 2012, 102, 1130-1142. [CrossRef] [PubMed]

9. Sawamura, K.; Yukita, K. Alternaria blotch. In Compendium of Apple and Pear Diseases and Pests; Sutton, T.B., Aldwinckle, H.S., Agnello, A.M., Walgenbach, J.F., Eds.; American Phytopathological Society: St. Paul, MN, USA, 2014; pp. $32-33$.

10. Soleimani, M.J.; Esmailzadeh, M. First report of Alternaria mali causing apple leaf blotch disease in Iran. Aust. Plant Dis. Notes 2007, 2, 57-58. [CrossRef]

11. Gur, L.; Reuveni, M.; Cohen, Y. Occurrence and etiology of Alternaria leaf blotch and fruit spot of apple caused by Alternaria alternata f. sp. mali on cv. Pink lady in Israel. Eur. J. Plant Pathol. 2017, 147, 695-708. [CrossRef]

12. Ferree, D.C.; Warrington, I.J. Apples: Botany, Production and Uses; CABI Publishing: Wallingford, UK, 2003.

13. Zhu, L.; Ni, W.; Liu, S.; Cai, B.; Xing, H.; Wang, S. Transcriptomics analysis of apple leaves in response to Alternaria alternata apple pathotype infection. Front. Plant Sci. 2017, 8, 22. [CrossRef] [PubMed]

14. Filajdic, N.; Sutton, T.B.; Walgenbach, J.F.; Unrath, C.R. The influence of European red mites on intensity of Alternaria blotch of apple and fruit quality and yield. Plant Dis. 1995, 79, 683-690. [CrossRef]

15. Filajdic, N.; Sutton, T.B.; Walgenbach, J.F.; Unrath, C.R. The influence of the Apple Aphid/Spirea Aphid complex on intensity of Alternaria blotch of apple and fruit quality characteristics and yield. Plant Dis. 1995, 79, 691-694. [CrossRef]

16. Jung, K.H. Growth inhibition effect of pyroligneous acid on pathogenic fungus, Alternaria mali, the agent of Alternaria blotch of apple. Biotechnol. Bioprocess. Eng. 2007, 12, 318-322. [CrossRef]

17. Stern, R.; Ben-Arie, R.; Ginzberg, I. Reducing the incidence of calyx cracking in 'Pink Lady'apple using a combination of cytokinin (6-benzyladenine) and gibberellins $\left(\mathrm{GA}_{4+7}\right)$. J. Hortic. Sci. Biotechnol. 2013, 88, 147-153.

18. Gur, L.; Reuveni, M.; Cohen, Y. Phenology based management of Alternaria fruit rot in Pink Lady apples. Plant Dis. 2018, 102, 1072-1080. [CrossRef]

19. Li, Y.; Aldwinckle, H.S.; Sutton, T.; Tsuge, T.; Kang, G.; Cong, P.H.; Cheng, Z.M. Interactions of apple and the Alternaria alternata apple pathotype. Crit. Rev. Plant Sci. 2013, 32, 141-150. [CrossRef]

20. Gur, L.; Reuveni, M.; Cohen, Y. Control of Alternaria fruit rot in 'Pink Lady' apples by fungicidal mixtures. Crop. Prot. 2020, 127, 104947. [CrossRef]

21. Cohen, Y. $\beta$-Aminobutyric acid induces systemic resistance against Peronospore tabacina. Physiol. Mol. Plant Pathol. 1994, 44, 273-288. [CrossRef]

22. Cohen, Y. Local and systemic control of Phytophthora infestans in tomato plants by DL- $\beta$-amino-n-butanoic acids. Phytopathology 1994, 84, 55-59. [CrossRef] 
23. Cohen, Y. Induced resistance against fungal diseases by aminobutyric acids. In Modern Fungicides and Antifungal Compounds; Lyr, H., Russel, P.E., Sisler, H.D., Eds.; Intercept: Andover, UK, 1996; pp. 461-466.

24. Cohen, Y. $\beta$-aminobutyric acid-induced resistance against plant pathogens. Plant Dis. 2002, 86, 448-457. [CrossRef] [PubMed]

25. Cohen, Y.; Vaknin, M.; Mauch-Mani, B. BABA-induced resistance: Milestones along a 55-year journey. Phytoparasitica 2016, 44, 513-538. [CrossRef]

26. Justyna, P.G.; Ewa, K. Induction of resistance against pathogens by $\beta$-aminobutyric acid. Acta Physiol. Plant 2013, 35, 1735-1748. [CrossRef]

27. Oka, Y.; Cohen, Y.; Spiegel, Y. Local and systemic induced resistance to the root-knot nematode in tomato by DL- $\beta$-amino-n-butyric acid. Phytopathology 1999, 89, 1138-1143. [CrossRef]

28. Reuveni, M.; Sheglov, D.; Cohen, Y. Control of moldy-core decay in apple fruits by ß-aminobutyric acids and potassium phosphites. Plant Dis. 2003, 87, 933-936. [CrossRef]

29. FRAC (Fungicide Resistance Action Committee). FRAC Code List: Fungicides Sorted by Mode of Action (Including FRAC Code Numbering). Available online: https:/ / www.frac.info/home/news/2020/02/18/the-updated-frac-code-list-2020-is-nowavailable-for-download (accessed on 1 March 2020).

30. Lyon, G.D.; Newton, A.C. Do resistance elicitors offer new opportunities in integrated disease control strategies? Plant Pathol. 1997, 46, 636-641. [CrossRef]

31. Elsherbiny, E.A.; Dawood, D.H.; Safwat, N.A. Antifungal action and induction of resistance by $\beta$-aminobutyric acid against Penicillium digitatum to control green mold in orange fruit. Pestic. Biochem. Physiol. 2021, 171, 104721. [CrossRef] [PubMed]

32. Ozgonen, H.; Karatas, A. Effect of salicylic acid, DL-beta-amino-n butyric acid and Acibenzolar-s-methyl+ metalaxyl on mycelial growth and spore germination of Alternaria mali in vitro and on young apple seedlings. Int. J. Agric. Biol. 2013, 15, 165-169.

33. Cohen, Y.; Reuveni, M.; Baider, A. Local and systemic activity of BABA (DL- $\beta$ - aminobutyric acid) against Plasmopara viticola in grapevines. Eur. J. Plant Pathol. 1999, 105, 351-361. [CrossRef]

34. Cohen, Y.; Rubin, A.E.; Vaknin, M. Post infection application of DL- $\beta$ - amino-butyric acid (BABA) induces multiple forms of resistance against Bremia lactucae in lettuce. Eur. J. Plant Pathol. 2011, 130, 13-27. [CrossRef]

35. Baccelli, I.; Mauch-Mani, B. Beta-aminobutyric acid priming of plant defense: The role of ABA and other hormones. Plant Mol. Biol. 2016, 91, 703-711. [CrossRef] [PubMed]

36. Chavan, V.; Kamble, A. Induction of total phenolics and defence-related enzymes during $\beta$-aminobutyric acid-induced resistance in Brassica carinata against Alternaria blight. Arch. Phytopathol. Plant Protect. 2014, 47, 2200-2212. [CrossRef]

37. Luna, E.; van Hulten, M.; Zhang, Y.H.; Berkowitz, O.; Lopez, A.; Petriacq, P.; Ton, J. Plant perception of $\beta$-aminobutyric acid is mediated by an aspartyl-tRNA synthetase. Nat. Chem. Biol. 2014, 10, 450-456. [CrossRef] [PubMed]

38. Schwarzenbacher, R.E.; Wardell, G.; Stassen, J.; Guest, E.; Zhang, P.; Luna, E.; Ton, J. The IBI1 receptor of $\beta$-aminobutyric acid interacts with $\mathrm{VOZ}$ transcription factors to regulate abscisic acid signaling and callose-associated defense. Mol. Plant 2020, 13, 1455-1469. [CrossRef] [PubMed]

39. Li, J.; Trivedi, P.; Wang, N. Field evaluation of plant defense inducers for the control of citrus huanglongbing. Phytopathology 2016, 106, 37-46. [CrossRef]

40. Hwang, B.K.; Yun, J.H. Variability in sensitivity to polyoxin B of isolates of Alternaria mali and decreased fitness of polyoxin resistant isolates. J. Phytopathol. 1986, 115, 305-312. [CrossRef]

41. Lee, C.U.; Kim, K.H. Cross-tolerance of Alternaria mali to various fungicides. Korean J. Mycol. 1986, 14, 71-78.

42. Lu, Y.L.; Sutton, T.B.; Ypema, H. Sensitivity of Alternaria mali from North Carolina apple orchards to pyraclostrobin and boscalid. Phytopathology 2003, 93, S54.

43. Van den Bosch, F.; Paveley, N.; van den Berg, F.; Hobbelen, P.; Oliver, R. Mixtures as a fungicide resistance management tactic. Phytopathology 2014, 104, 1264-1273. [CrossRef] 